\title{
Use and Origin of Yerba Maté*
}

\section{By CAPt. T. A. Joyce, o.B.E.}

INFUSIONS from vegetable products are common throughout the world, but the particular infusion with which this address deals is that procured from the leaves and shoots of the Ilex paraguayensis, a shrub indigenous to Paraguay and to southern Brazil. After a process of drying, aided by fire, hot water is poured on the broken or powdered leaf, and the infusion is imbibed through a tube of silver or of native bamboo. From the centre of its origin it spread rapidly, like all valuable food products, to the Argentine, Chile and Peru, and, especially since the War, when many South American contingents were engaged, it has become more familiar in Europe than formerly.

The particular virtue of the drink is that it contains little or no tannin, combines favourably with a meat diet, and can be repeatedly refreshed by hot water without deleterious effects. In South America, especially amongst the Gaucho class, it used to take the place of fruit and vegetables, for it is an antiscorbutic of considerable value. Thousands of tons are used in South America annually.

Mixed with cold water, it provides a very refreshing beverage, but the normal method of taking the drink is in the hot infusion. When lukewarm it is regarded as a violent aperient. Two appliances are used, the maté, a gourd or silver cup in which the decoction is prepared, and a tube, the bombilla, through which the infusion is drunk. The word for the receptacle (maté) became transferred to the leaf and the drink; both are now generally known under that name, especially in Europe.

The first mention of the drink in published literature occurs in a book by Nicolás Durán, a Jesuit missionary in Paraguay in the early seventeenth century. Durán travelled through the province of Guaira and visited the Jesuit missions at Villa Rica, San Xavier, Loreto and San Ignacio; all these regions were, at that time, centres of yerba maté preparation and of distribution.

Translated from the Latin, Durán writes as follows :

"The most severe labour to which the Indians are put consists in being sent by their masters to Maracaiu, to collect the foliage of certain trees growing in the mountains and forests. These trees, not unlike laurels, but of a brighter green, flourish especially in moist and swampy woods.

\footnotetext{
- Presidential address to Section H (Anthropology) of the British
} Association, delivered at Aberdeen on September 10.
The leaves, after being parched in a fire, are pounded in mortars, and, when reduced to dust, are packed in cases, and carried many miles on the backs of the Indians. On account of the unhealthiness of the climate, and the scarcity of food, which their poverty-stricken masters cannot provide, these unhappy Indians are forced to subsist on snakes, grubs and spiders. And so, worn out by contagious diseases and famine, they die. It is a pitiable picture, for, in return for their labour, all they receive when they return from this slavery is a beggarly two yards of cloth. Some even go home empty-handed, because the Spaniards themselves are extremely poor. The Spaniards sell the powder of this herb (which they call 'Herb' par excellence) to traders who come hither (Guaira), or rather exchange it for necessaries. And it often happens that 2,000 lbs. of this powder is given for a suit of common cloth, or $500 \mathrm{lbs}$. for a hat. Spaniards and Indians of both sexes drink this powder, mixed with hot water, once or twice daily, which proves a most efficacious emetic. So much are they slaves of this habit, that they will barter shirt, trousers or bedding for it. An instance is known where a woman stripped her hut of its roofing in order to buy this herb. They say too that their strength fails, and that they cannot live, if they are deprived of its use. The Indians take it at daybreak and at frequent intervals during the day. It has come to be such a vice in these provinces that all the inhabitants of the River Plate, Tucu. man and Chile make use of it. So that in Potosí, and throughout Peru, $1 \mathrm{lb}$. of this herb is sold for four golden crowns. This herb makes men gluttons, slaves to their bellies, and renders them averse to work of any kind. And its efficacy appears to lie more in the imagination of him who uses it than its own inherent virtue."

By the middle of the seventeenth century, Nicolas del Techo (du Toict), who became Superior of the Province of Paraguay, as a Jesuit missionary, writes of the use of the drink as follows:

"In Paraguay, for a long time, sugar and cotton, both produced in small quantities, were the chief wealth, till the leaves of a certain tree, growing in marshy grounds, commonly called the Herb of Paraguay, began to be in esteem. These leaves they dry in the fire and reduce to powder; then, mixing with hot water, the Spaniards and Indians, both men and women, drink of it several times a day; and, vomiting it up with all they have eaten, they find it creates an appetite. Many things are reported concerning this powder or herb; for they say if you cannot sleep, it will compose you to it; if you are lethargick, it drives away sleep; if you are hungry it satisfies; if your meat does not digest, it causes an appetite; it 
refreshes after weariness and drives away melancholy and several diseases. Those who once use themselves to it cannot easily leave it, for they affirm, their strength leaves them when they want it and can't live long: and so great slaves are they to this slender diet, that they will almost sell themselves rather than want wherewithal to purchase it. 'The wiser sort (tho', moderately used, it strengthens and brings other advantages) will hardly ever make use of it ; and, if immoderately used, it causes drunkenness and breeds distempers, as too much wine does. Yet this vice has not only overrun Paraguay, but Tucuman, Chile and Peru. And is near coming over into Europe; this Herb of Paraguay being valued amongst the precious commodities of America. At first the Spaniards were well pleas'd with their cotton garments and liquor made of honey. But afterwards, trade enhancing the value of this herb, covetousness and luxury encreas'd, to feed both which the Indians began to be enslav'd to make this powder. Labour made their numbers decrease, and that made the Spaniards poor again ; to show us that very often the same methods we take to gather wealth serve to impoverish us."

The two quotations given above are couched in rather harsh terms in regard to the excessive use of the ilex; but the same could be written of tea, or any infusion, or of alcoholic drinks, if taken in excess. However, Southey, writing in 1817, avers that over-indulgence has been known to result in almost total mental aberration, lasting over many days; and the danger of serious infection, owing to the use of a common bombilla, which passes from lip to lip, is emphasised by many writers. Demersay adds that the constant imbibing of hot maté, alternating with draughts of cold water, is bad for the teeth, and suggests that the use of a silver bombilla, which can become unbearably hot, may cause cancer in the lip.

As regards the properties of the ilex, which have won for it so widespread a popularity, authorities are not quite in accord. Christy (1880) states that the leaf contains "the same active property as tea or coffee, in a proportion (nearly 2 per cent) intermediate between the two; a volatile oil ; 16 per cent of an astringent principle ; and about 10 per cent of a nutritious gluten, only a portion of which is dissolved in the infusion." He states further that the full benefit of the leaf is only obtained when it is chewed.

The "Handbook of Paraguay" (1894) gives the analysis as 0.45 caffeine, 20.88 caffeo-tannic acid, an aromatic oil, gluten and a proportion of theine. However, we may conclude that the action of the infusion would be that of a cardiac and a nutritive, while the relatively small proportion of tannin would render it more digestible than tea. It is, perhaps, a little strange that the earliest authors who record its use, Durán (1626-27), Leon Pinelo (1636) and del Techo (1649-72), quote it primarily as an emetic.

To leave aside for the moment the question of the actual discovery of the properties of yerba maté, the initial exploitation of the 'tea' was undoubtedly due to the Jesuit missionaries. The first Jesuit reservation was founded in 1609, the last in 1760, and the Jesuits were expelled in 1774. The missionaries encouraged the use of the leaf among their Indians, to whom it was served out with other rations ; and Endlicher and Martius state that this was done to wean the natives from over-indulgence in fermented drinks. But there is no doubt that the revenues derived from the trade in the leaf became indispensable to these self-supporting communities, whose establishment is one of the most remarkable developments in the world's history. On the expulsion of the Jesuits, their mission houses and lands became Crown property, and the maté industry had become so prosperous that, in 1807, the profits derived from it were reckoned at $£ 100,000$ annually.

Long before this, in the seventeenth and eighteenth centuries, the leaf had become an article of trade to the western provinces of the Argentine, to Uruguay, Chile, Peru, Bolivia and Ecuador. The chief collecting region was the Maracayu district. Asunción was the outlying depot, whence the produce was sent by river to Santa Fé, on the Paraná, the chief depot for external trade. Frézier (1712-14) writes that the ordinary route was from Santa Fé to Jujuy in the Argentine by wagon and thence to Potosí in Bolivia by mule-back. Chile, according to Juan and Ulloa (1740-44), was supplied direct from Buenos Ayres, and passed supplies on to Peru.

The most vivid and detailed account of what had developed into a well-organised industry was given by the Robertsons in the first half of the nineteenth century. Then, the chief collecting regions, the montes, or woods where the ilex flourished, were near Villa Real, about one hundred and fifty miles up river from Asunción. The work of collecting was lucrative, but so arduous that it was usually performed by newcomers and men in debt. These concessionaires were financed or 'grub-staked' by merchants of Asunción, who expected repayment in the form of yerba.

Each concessionaire hired twenty to fifty workers, and the difficult journey through untracked forest to the ilex groves (yerbales) ended when a promising locality was reached; here, camping-ground was prepared for a stay of six months or so, with huts for the personnel and corrals for the mules and oxen. The tatacua, a 
space some six feet square of hard-beaten earth, with a post at each corner, was made ready for the preliminary curing of the leaf, a simple process of scorching the masses of verdure over burning logs.

Nearby, the barbacua was prepared, an arch of boughs supported on trestles; upon this arch the ilex leaves, now readily separated from large twigs and boughs, were placed for the secondary drying. The fire built below the arch was carefully tended to prevent the leaves from burning, and to ensure complete drying; and, when the process was complete, the barbacua and the ashes of the fire were removed, the ground swept and beaten smooth, and the dried ilex leaves placed on it, and pounded with wooden mallets.

The powdered or broken leaf was then packed tightly into sacks made from freshly flayed bulls' hides (serones), sewn up and left to dry. Each seron weighed 200-220 lb. when dry. A similar process is employed to-day.

(To be continued.)

\section{Ascorbic Acid (Vitamin C)}

THE discussion on ascorbio acid (vitamin $\mathrm{C}$ ) 1 which was held in Section B (Chemistry) at the recent meeting of the British Association was, as the official title of the discussion indicated, mainly devoted to the chemical aspect of the subject. Perhaps the chief impression brought away from the meeting was of the astonishing advance made in our knowledge of vitamin $\mathrm{C}$ since Tillmans and Hirsch in 1932, after discovering that the vitamin could undergo a reversible oxidation without loss of potency, pointed out the great similarity between its properties and those of Szent-Györgyi's hexuronic acid (now known as ascorbic acid) and suggested that the latter substance might itself be the vitamin.

The speedy confirmation of this suggestion by Szent-Györgyi himself, followed by many other workers, led to an intensive study of the chemistry of ascorbic acid, which resulted in the synthesis of the compound (1933) dowered with the full antiscorbutic potency of the natural substance. As has so often happened, it has also led to the synthetic production of numerous substances of similar composition, none of which has so far been found in plants or animals, but some of which are possessed of substantial antiscorbutic power, in all cases up to the present considerably less than that of ascorbic acid itself. A new chapter in the study of the relations between physiological properties and chemical constitution has thus been opened and many interesting results have already been obtained.

Conflicting results were obtained by different investigators as to the constitution of ascorbic aeid, but further experience has decided in favour of that worked out by Dr. E. L. Hirst and his colleagues at the University of Birmingham as against that of the Swiss workers Micheel and Kraft. Nevertheless, both formulæ served to inspire the successful synthesis of the acid, which was independently effected by the same method at Birmingham (Haworth and colleagues) and at Zurich (Reichstein and colleagues) - not the first occasion, as Dr. Reichstein remarked, on which synthetic studies, though based on incorrect suppositions, have turned out successfully.

The original synthesis from $l$-xylosone by way of the hydroxynitrile

$$
\begin{aligned}
& \mathrm{CH}_{2} . \mathrm{OH} . \mathrm{CH}(\mathrm{OH}) . \mathrm{CH}(\mathrm{OH}) . \mathrm{CO} \cdot \mathrm{CHO} \longrightarrow \longrightarrow \\
& \mathrm{CH}_{2} . \mathrm{OH} . \mathrm{CH}(\mathrm{OH}) . \mathrm{CH}<\begin{array}{c}
\mathrm{O}-\mathrm{CO}_{\mathrm{C}}(\mathrm{OH}): \mathrm{C}(\mathrm{OH}) \\
<
\end{array}
\end{aligned}
$$

suffers from the disadvantage that the raw material of the synthesis is difficult to prepare in quantity. It is, however, a general method and can be applied to other osones, leading to the production of the corresponding 'ascorbic acids'. Among the results which followed rapidly on the synthesis of $l$-ascorbic acid were the preparation. of $d$-ascorbic acid, from $d$-xylosone, and of the corresponding products from the arabinosones, $d$-arabo-ascorbic acid and $l$-arabo-ascorbic acid. Of these four isomerides, $l$-ascorbic acid has the full antiscorbutic potency of the natural acid; $d$-ascorbic acid is quite inactive, so far as it has been tested; $d$-arabo-ascorbic acid possesses about one twentieth of the activity of $l$-ascorbic acid and $l$-arabo-ascorbic acid is quite inactive. $l$-Rhamno-ascorbic acid, prepared from rhamnosone (Reichstein) has about one fifth of the activity of $l$-ascorbic acid, the highest value yet found in any analogue of the natural acid.

The osones of the hexoses yield the corresponding 'ascorbic acids' containing seven carbon atoms. The derivatives of $d$-glucosone and $d$-galactosone are inactive, whilst that of $l$-glucosone has a slight activity, about one fortieth of that of the natural acid.

The tentative conclusion drawn from the data so far available is that the antiscorbutic activity of the substance is, in the first instance, correlated with the configuration of the fourth carbon atom, which in $l$-ascorbic acid is the optically active carbon atom of the ring. If the configuration about this carbon atom is dextro, as in $l$-ascorbic acid, the substance possesses anti- 